\title{
Modelo numérico del proceso de reestenosis tras la implantación de un stent
}

\author{
Javier Escuer Gracia ${ }^{1}$, Estefanía Peña Baquedano ${ }^{1,2}$, Miguel Ángel Martínez Barca ${ }^{1,2}$ \\ ${ }^{1}$ Applied Mechanics and Bioengineering (AMB) \\ Instituto de Investigación en Ingeniería de Aragón (I3A) \\ Universidad de Zaragoza, Mariano Esquillor s/n, 50018, Zaragoza, Spain. \\ Tel. +34-976762707, e-mail: jescuer@unizar.es \\ ${ }^{2}$ Centro de Investigación en Red en Bioingeniería, Biomateriales y Nanomedicina (CIBER-BBN)
}

\section{Abstract}

En este trabajo se presenta un modelo numérico continuo basado en una geometría 2D aximétrica para reproducir el proceso de reestenosis que tiene lugar, probablemente en todos los pacientes, después de la implantación de un stent farmacoactivo (DES) en una arteria coronaria.

\section{Introducción}

Los stents liberadores de fármacos (DES) son los dispositivos endovasculares más utilizados actualmente a la hora de corregir el estrechamiento (estenosis) producido por las placas de ateroma en las arterias coronarias. Sin embargo, uno de los problemas más frecuentes que se presenta después de este tipo de intervenciones quirúrgicas es el crecimiento excesivo de tejido debido a una cadena de procesos inflamatorios que se producen dentro de la sección de la arteria donde se aplicó el tratamiento, ocasionando que vuelva a obstruirse de nuevo. Esta complicación es conocida como reestenosis [1]. De forma complementaria a la amplia variedad de estudios experimentales, la simulación computacional se ha convertido en una potente herramienta que aporta un mejor entendimiento de los factores físicos que influyen en los diferentes procesos biológicos que tienen lugar en el tejido. En este trabajo, se presenta un modelo computacional continuo que reproduce el proceso de reestenosis, describiendo el balance de masa que tiene lugar entre diferentes especies biológicas en la pared arterial mediante ecuaciones de conveccióndifusión-reacción. Las principales especies que intervienen en el proceso de reestenosis son las células musculares lisas (SMC), células endoteliales (EC), metaloproteinasas (MMP), factores de crecimiento (GF) y la matriz extracelular (ECM).

\section{Materiales y métodos}

Se desarrolla un modelo numérico multicapa compuesto por siete regiones que incluyen lumen, endotelio, espacio subendotelial o intima, lámina elástica interna, capa media, lámina elástica externa y adventicia, correspodiente a una representación 2D idealizada de un segmento recto de una arteria coronaria (Figura 1). Sin embargo, los procesos que conducen a la aparición de la reestenosis tienen lugar principalmente en la intima y en la capa media. La aplicación del daño en el modelo computacional es asumida como consecuencia directa del nivel de tensión que aparece en la pared arterial después de la implantación del stent. La producción de las distintas especies biológicas y la reacción entre las mismas en respuesta al daño mecánico ocasionado por el dispositivo, se simulan a través de un modelo continuo basado en ecuaciónes de difusión-reacción. Se consideran tres tipos de células (células musculares lisas, en su fenotipo contráctil y sintético y células endoteliales) y tres tipos de componentes extracelulares (matriz extracellular, metaloproteinasas y factores de crecimiento). Los diferentes tipos de células relevantes para la mayoría de los modelos mecobiológicos existentes en la literatura tienen un conjunto limitado de comportamientos: proliferación, migración, diferenciación, absorción de sustancias químicas y apoptosis, mientras que las sustancias que pertenecen a la pared arterial pueden ser producidas o degradadas [2]. Los procesos biológicos que conducen a la aparición de la reestenosis han sido descritos matemáticamente y las constantes que definen la interacción biológica entre las diferentes especies se han obtenido a partir de estudios experimentales existentes en la literatura. El software comercial COMSOL Multiphysics 5.2 (COMSOL AB, Burlington, MA, USA) ha sido utilizado para desarrollar el modelo computacional y para resolver, mediante el método

Revista "Jornada de Jóvenes Investigadores del I3A", vol. 5 (Actas de la VI Jornada de Jóvenes Investigadores del I3A - 2 de junio de 2017). ISSN 2341-4790. 
de los elementos finitos (MEF), las distintas ecuaciones diferenciales en derivadas parciales planteadas.

\section{Resultados}

Se puede observar como para un tiempo $t=0$ los valores de daño son máximos en zonas cercanas a los struts del stent, obteniéndose valores cada vez más bajos conforme nos alejamos del dispositivo. Para tiempo $t=200$ días el daño es prácticamente inexistente en todo el modelo (Figura 2).

\section{Conclusiones}

Los resultados obtenidos muestran como este modelo es válido para predecir la evolución de las especies consideradas así como para captar los aspectos más relevantes del crecimiento de la lesión y del proceso de cicatrización en una arteria coronaria sometida a fuerzas mecánicas no fisiológicas. Nuestros resultados sugieren que la respuesta de la pared arterial es principalmente causada por el área endotelial dañada por el dispositivo y a la pérdida de colágeno que se produce, entre otros factores.

\section{Agradecimientos}

Este estudio ha sido financiado por el Ministerio de Economía, Industria y Competitividad de España (MINECO) a través de la beca BES-2014-069737 y el proyecto DPI2016-76630-C2-1-R.

\section{REFERENCIAS}

[1]. Boyle, C.J., Lennon, A.B., Prendergast, P.J.,2011.In silico prediction of the mechanobiological response of arterial tissue: application to angioplasty and stenting.J. Biomech. Eng.133 (August),1-10.

[2]. NICOLÁS M, PEÑA E, MALVÈ M, MARTÍNEZ MA.Mathematical modeling of the fibrosis process in the implantation of inferior vena cava filters. J Theor Biol (2015) 387:228-40.10.1016/j.jtbi.2015.09.028.

\section{FIGURAS / LEYENDAS}

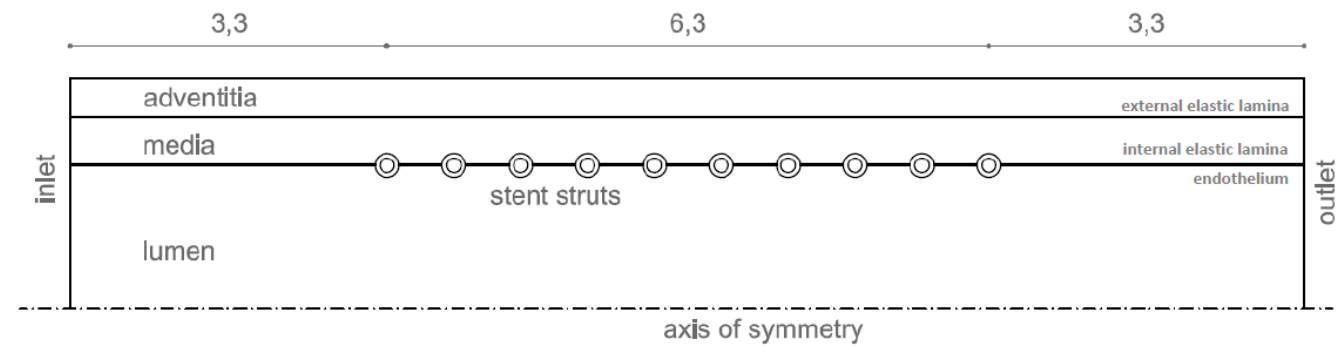

Figura 1. Geometría del modelo (mm)
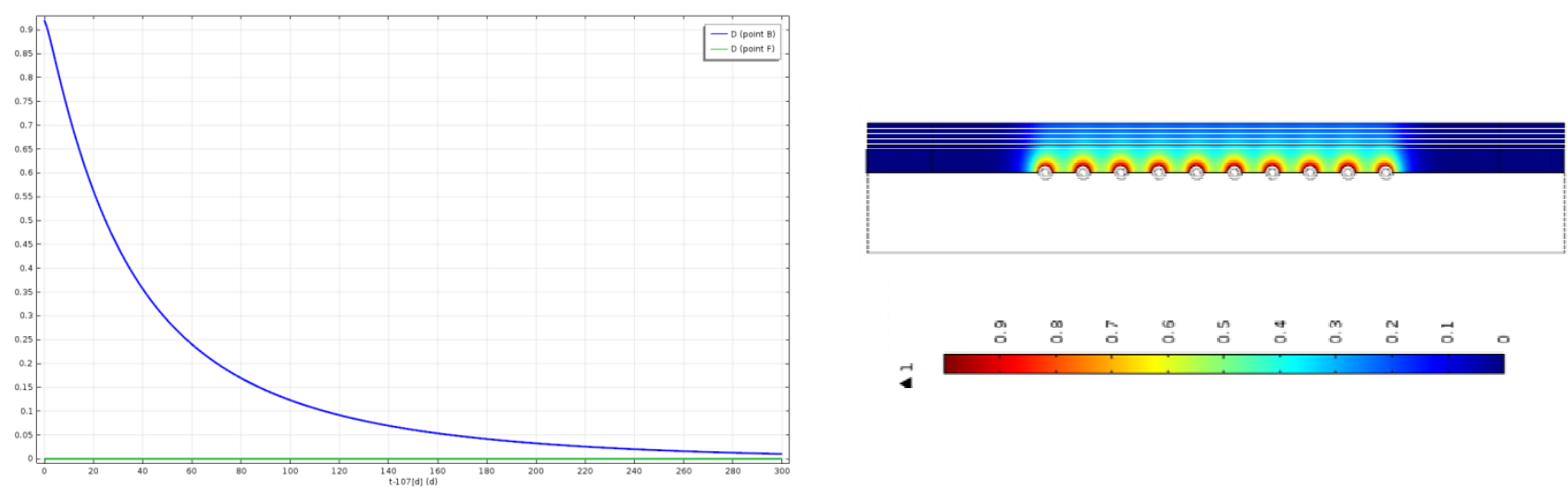

Figura 2. A la izquierda, evolución temporal del daño producido por el stent en la capa media de la arteria. A la derecha, representación del daño en la pared arterial tras la impantación del dispositivo $(\mathrm{t}=0)$. 